\title{
Accuracy Evaluation and Parameter Analysis of Land Surface Temperature Inversion Algorithm for Landsat-8 Data
}

\author{
Jikang Wan $\left(\mathbb{D},{ }^{1}\right.$ Min Zhu $\mathbb{D D}^{1,2}$ and Wei Ding $\mathbb{D}^{3}$ \\ ${ }^{1}$ Hohai University, College of Computer and Information, Nanjing 211100, China \\ ${ }^{2}$ Yellow River Institute of Hydraulic Research, Zhengzhou 450003, China \\ ${ }^{3}$ University of Calgary, Department of Geomatics Engineering, Calgary AB T2N 1N4, Canada \\ Correspondence should be addressed to Min Zhu; 190207050001@hhu.edu.cn
}

Received 3 August 2021; Revised 29 August 2021; Accepted 8 September 2021; Published 24 September 2021

Academic Editor: Stefania Bonafoni

Copyright ( $\odot 2021$ Jikang Wan et al. This is an open access article distributed under the Creative Commons Attribution License, which permits unrestricted use, distribution, and reproduction in any medium, provided the original work is properly cited.

Many researchers have developed a variety of land surface temperature (LST) inversion algorithms based on satellite data. The main LST inversion algorithms include Radiative Transfer Equation (RTE), Single Channel (SC) algorithm, Mono Window (MW) algorithm, and Split Window (SW) algorithm. In this study, nine LST inversion algorithms were designed using Landsat-8 data and meteorological station data to test the inversion efficiency of different algorithms in different seasons and different locations. The results show that the error of various LST inversion algorithms will increase with the rise of LST. $R^{2}$ of the inversion results of each LST algorithm and the measured data are all greater than $0.73^{\circ} \mathrm{C}$ in winter and about $0.5^{\circ} \mathrm{C}$ in the other seasons. By analyzing the stability of various algorithms inside and outside the city, it is found that the stability of each LST inversion algorithm inside the city is better than that outside the city. For the same surface features, the inversion temperature inside the city is $3-5^{\circ} \mathrm{C}$ higher than that outside the city. In addition, the sensitivity of various inversion algorithms to parameters was also analyzed. The influence of atmospheric transmittance on RTE, SC, and MW inversion algorithms is in logarithmic form. The effect of emissivity on each algorithm is linear. The influence of NDVI on the algorithms is mainly through the estimation of surface emissivity parameters to affect the inversion results. The effect of ascending radiation on SC (LST4 and LST5) is linear and on RTE (LST1 and LST2) is logarithmic. The effect of downslope radiation on SC and RTE is linear. The influence of atmospheric water vapor content on SW (LST7) is nonlinear.

\section{Introduction}

Land surface temperature (LST) is an essential parameter in many research fields, such as ecology, climatology, urban thermal environment, urban heat island, and hydrology [1-3]. Especially in recent years, more attention has been paid to carbon dioxide emissions $[4,5]$, polar climate warming and glacier melting [6,7], urban heat island (UHI) [8-10], urban heatwave and human living health [11], forest fires [12], drought monitoring [13], soil evapotranspiration [14], and precipitation and surface runoff $[15,16]$. The traditional LST measurement method is based on the temperature measurement data of meteorological stations for further spatial interpolation, which is a classical pointbased measurement method [17]. Although this method has high accuracy, the point-based temperature measurement method cannot represent the regional temperature. The timeliness of the method is insufficient. With the development and research of space-based infrared remote sensing, it is more and more popular to use satellite remote sensing to retrieve regional and global surface temperatures.

In many satellite observation systems equipped with thermal infrared sensors, Landsat satellites have become one of the most widely used satellites due to their observation history of more than 40 years. Since its launch on February 11,2013 , the newest generation of Landsat- 8 has been in orbit for more than eight years. It has sent back a large amount of Earth observation data at a rate of 550 images per day. Together with Landsat-7 ETM+, it forms a repeated observation period with an interval of 8 days, which provides precious data for monitoring ecological environment changes on the Earth's surface. Because of its advantages of 
high spatial resolution, large scanning field of view, and accessible data, researchers have applied it to further scientific research and ecological construction.

Since the launch of Landsat-8, various processing documents and parameters have been posted on the Landsat. Many researchers have developed a variety of LST inversion algorithms based on Landsat-8. The main LST inversion algorithms include the Radiative Transfer Equation (RTE) [18, 19], Single Channel (SC) algorithm [20, 21], Mono Window (MW) algorithm [22], and Split Window (SW) algorithm [21, 23-25]. In these surface temperature inversion algorithms, multiple basic parameters are needed for input [26]. The multiple parameters are estimated variables rather than standard ones. Accurate and reliable inversion algorithms should calculate the accuracy of the LST data used in the study to make the use of the product possible. If the inversion algorithm has a significant systematic error or a significant instability error, the algorithm or product will not be popular among users [27].

In this study, LST inversion, spatial analysis, and multiscale analysis methods were considered for Landsat data representing four seasons. The commonly used LST inversion algorithms are evaluated. First of all, we designed nine remote sensing inversion schemes for LST. We fitted the LST calculated by the satellite with the measured temperature values at the ground stations at the same time. Based on the same scene remote sensing data, the accuracies of the nine inversion algorithms were compared and analyzed. The accuracy of each LST inversion algorithm on the time scale was analyzed separately on the images of different seasons. Then, the inversion accuracies of all the LST inversion methods on the regional scale (inside city and outside city) of the same surface features are compared and analyzed. Finally, we test the dependence of each inversion algorithm on parameters by equal step size. The aims of this study are as follows: (1) evaluate the errors of multiple inversion algorithms on the same scene data, (2) evaluate the error of each inversion algorithm in seasons (spring, summer, autumn, and winter), (3) evaluate the regional error of each inversion algorithm, and (4) perform dependence intensity and sensitivity analysis of the evaluation algorithm on parameters.

\section{Study Areas and Data Compilation}

2.1. Study Areas. The study area was selected as an area covered by Landsat- 8 data (orbit number 123, 032). The longitude and latitude of the data center are $40.3^{\circ} \mathrm{N}$ and $116.7^{\circ} \mathrm{E}$. It mainly covers Beijing, the capital of China. The climate type in the study area is semihumid and semiarid monsoon climate in the warm temperate zone, with four distinct seasons, hot and rainy in summer and cold and dry in winter. It provides a natural, convenient condition for studying the difference of inversion algorithms on a seasonal scale.

2.2. Data Compilation. This study contained four pieces of Landsat- 8 data based on USGS (United States Geological Survey, https://www.usgs.gov/). Landsat-8 has 11 bands, of which seven multispectral bands have a spatial resolution of $30 \mathrm{~m}$. Through resampling, the spatial resolution of the two thermal infrared bands is also $30 \mathrm{~m}$. The revisit period is 16 days for global coverage. Since the surface reflectance is affected by the atmospheric conditions at the time of image acquisition and it is also a potential factor for studying the surface thermal model, when screening the data, we select the imaging data under good weather condition, which was a clear day with less than $2 \%$ cloud cover, and use the thermal band data to retrieve the LST conduct research. In order to investigate the accuracy of the Landsat-8 land surface temperature inversion algorithm in season, the imaging dates of January 31, 2017 (winter), May 7, 2017 (spring), July 10, 2017 (summer), and October 30, 2017 (autumn), were selected. All images were named by the 8 -digit number of years, months, and day of the collection date for the convenience of recording. For example, the image on May 7, 2017, as shown in Figure 1, was named 2017-05-07.

This study also collected and sorted the surface temperature data of 20 meteorological stations in the study area. The basic information of the meteorological stations is shown in Table 1. The positions of these meteorological stations in the study area are shown in the red dots in Figure 1. The temperature data were collected from the China Meteorological Administration and measured simultaneously as remote sensing images. To study the accuracy of the inversion algorithm of the LST inside and outside the city, points of interest (POIs) were established for four kinds of ground objects (water, vegetation, soil, and building), and 20 POIs were established for each ground object. Pure pixels were selected for each point of interest from Landsat- 8 multispectral data. High-resolution Google Earth images also examined the selection of all POIs. As shown in Figure 1, those outside the city are represented by green dots, while yellow dots represent those inside the city.

\section{Methods}

3.1. Multispectral Image Processing. Using the Landsat-8 website, the user can convert the Digital Numbers (DNs) of the image to the spectral radiance of the top of the atmosphere (TOA). By applying the equation

$$
L_{\lambda}=M_{L} Q_{\text {cal }}+A_{L}
$$

where $L_{\lambda}\left(\right.$ Watts $\left.\cdot \mathrm{m}^{-2} \cdot \operatorname{srad}^{-1} \mu \mathrm{m}^{-1}\right)$ refers to the TOA spectral radiance, $M_{L}$ is the multiplicative rescaling factor of the corresponding band, it can be obtained from the header file of the data with the field "Radiance_Mult_Band_ $x=$, " $x$ stands for band number. $Q_{\text {cal }}$ is the pixel values, and $A_{L}$ is the offset of the data. The multispectral bands of Landsat- 8 data can also be converted to the reflectivity of the top of the atmosphere by the following equation:

$$
\rho_{\lambda}^{\prime}=M_{\rho} Q_{\mathrm{cal}}+A_{\rho}
$$

where $\rho_{\lambda}^{\prime}$ is the reflectance of the top of the atmosphere at band $\lambda$ without correction of the solar angle, $M_{\rho}$ is the reflectivity adjustment factor of band $\lambda$, and it can be obtained from the header file of the data with the field 

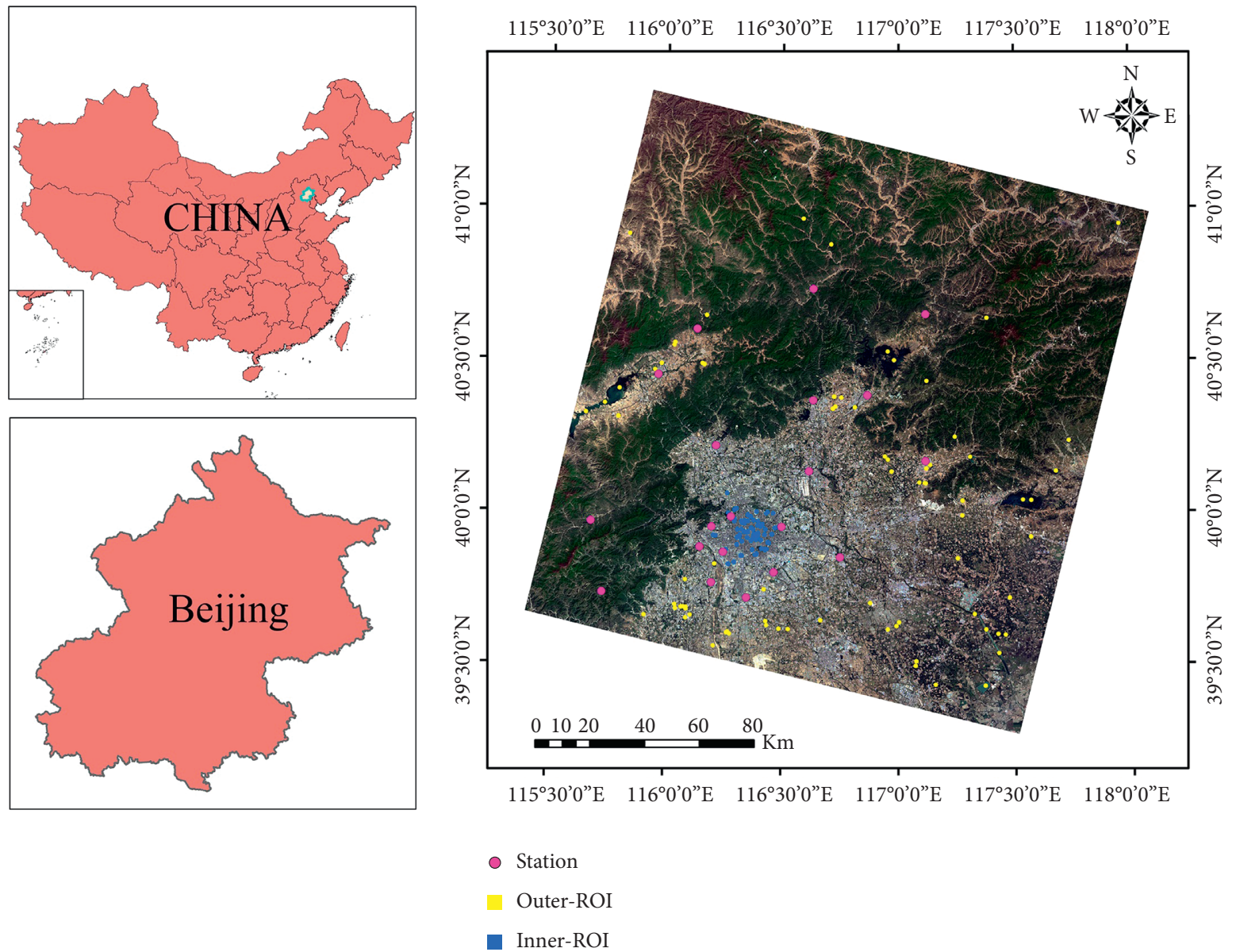

FIGURE 1: Study areas. The remote sensing data of “LC08_L1TP_123032_20170507_20170515_01_T1," displayed in true color, is named 2017-05-07, with red dots representing the location of the meteorological station, green dots representing the points of interest outside the city, and yellow dots representing the points of interest inside the city.

TABLE 1: Basic information of meteorological stations in the study area.

\begin{tabular}{|c|c|c|c|c|}
\hline Name & Latitude & Longitude & Elevation $(\mathrm{m})$ & Land cover type \\
\hline Shunyi & $40.13^{\circ} \mathrm{N}$ & $116.61^{\circ} \mathrm{E}$ & 28.6 & Grassland \\
\hline Haidian & $39.98^{\circ} \mathrm{N}$ & $116.28^{\circ} \mathrm{E}$ & 45.8 & Grassland \\
\hline Yanqing & $40.45^{\circ} \mathrm{N}$ & $115.96^{\circ} \mathrm{E}$ & 487.9 & Natural vegetation mosaic \\
\hline Foyeding & $40.60^{\circ} \mathrm{N}$ & $116.13^{\circ} \mathrm{E}$ & 1224.7 & Natural vegetation mosaic \\
\hline Tanghekou & $40.73^{\circ} \mathrm{N}$ & $116.63^{\circ} \mathrm{E}$ & 331.6 & Natural vegetation mosaic \\
\hline Miyun & $40.38^{\circ} \mathrm{N}$ & $116.86^{\circ} \mathrm{E}$ & 71.8 & Grassland \\
\hline Huairou & $40.37^{\circ} \mathrm{N}$ & $116.63^{\circ} \mathrm{E}$ & 75.7 & Grassland \\
\hline Shangdianzi & $40.65^{\circ} \mathrm{N}$ & $117.11^{\circ} \mathrm{E}$ & 293.3 & Natural vegetation mosaic \\
\hline Pinggu & $40.17^{\circ} \mathrm{N}$ & $117.11^{\circ} \mathrm{E}$ & 32.1 & Grassland \\
\hline Tongzhou & $39.85^{\circ} \mathrm{N}$ & $116.75^{\circ} \mathrm{E}$ & 19.8 & Grassland \\
\hline Chaoyang & $39.95^{\circ} \mathrm{N}$ & $116.50^{\circ} \mathrm{E}$ & 35.3 & Grassland \\
\hline Changping & $40.21^{\circ} \mathrm{N}$ & $116.21^{\circ} \mathrm{E}$ & 76.2 & Grassland \\
\hline Zhaitang & $39.96^{\circ} \mathrm{N}$ & $115.68^{\circ} \mathrm{E}$ & 440.3 & Natural vegetation mosaic \\
\hline Mentougou & $39.88^{\circ} \mathrm{N}$ & $116.15^{\circ} \mathrm{E}$ & 85.5 & Grassland \\
\hline Beijing & $39.80^{\circ} \mathrm{N}$ & $116.46^{\circ} \mathrm{E}$ & 31.3 & Grassland \\
\hline Shijingshan & $39.95^{\circ} \mathrm{N}$ & $116.20^{\circ} \mathrm{E}$ & 63 & Grassland \\
\hline Fengtai & $39.86^{\circ} \mathrm{N}$ & $116.25^{\circ} \mathrm{E}$ & 55.2 & Grassland \\
\hline Daxing & $39.71^{\circ} \mathrm{N}$ & $116.35^{\circ} \mathrm{E}$ & 37.5 & Grassland \\
\hline Fangshan & $39.76^{\circ} \mathrm{N}$ & $116.20^{\circ} \mathrm{E}$ & 48.9 & Grassland \\
\hline Xiayunling & $39.73^{\circ} \mathrm{N}$ & $115.73^{\circ} \mathrm{E}$ & 407.7 & Grassland \\
\hline
\end{tabular}


"Reflectance_Mult_Band_x=," where $x$ stands for band number. $A_{\rho}$ is the reflectivity adjustment parameter of band $\lambda$, the header file of the data with the field "Reflectance_Add_Band_ $x=. " \rho_{\lambda}^{\prime}$ can be further corrected by equation (3) into atmospheric top reflectivity $\rho_{\lambda}$ :

$$
\rho_{\lambda}=\frac{\rho_{\lambda}^{\prime}}{\cos \theta_{z}}=\frac{\left(M_{\rho} Q_{\mathrm{cal}}+A_{\rho}\right)}{\cos \theta_{z}},
$$

where $\theta_{z}$ is the solar zenith angle of the image center, and solar altitude angle $\theta_{E}$ can also be used, but sine function should be used. We used the solar altitude angle provided in the image for our calculations.

In this study, the COST model atmospheric correction algorithm of Pat and Chavez [28] is adopted to conduct Landsat-8 atmospheric correction. COST requires few parameters, and the correction is mainly carried out with the data of the image itself [29] by the following equation:

$$
\rho_{\lambda_{-} \cos t}=\frac{\left[M_{\rho}\left(Q_{\mathrm{cal}}-Q_{h}\right)+A_{\rho}\right]}{\cos \theta_{z} \tau},
$$

where $Q_{h}$ is the modification value of atmospheric influence, which can be obtained by the darkest pixel method, $\tau=\cos \left[\left(90-\theta_{z}\right) \pi / 180\right]$, and $\tau$ is the atmospheric transmittance estimated based on $\theta_{z}$. After COST atmospheric correction, NDVI (normalized difference vegetation index) is calculated by the following equation:

$$
\operatorname{NDVI}=\frac{\left(\rho_{\text {NIR_COST }}-\rho_{\text {red_COST }}\right)}{\left(\rho_{\text {NIR_COST }}+\rho_{\text {red_COST }}\right)},
$$

where $\rho_{\text {nir_COST }}$ is the reflectance image of the near infrared band and $\rho_{\text {red_COST }}$ is the reflectance image of the red band.

3.2. Thermal Infrared Image Processing. The brightness temperature (BT) can be calculated using the following equation:

$$
T=\frac{K_{2}}{\ln \left(\left(K_{1} / L_{\lambda}\right)+1\right)},
$$

where $T$ is the BT; $K_{1}$ and $K_{2}$ for the Landsat- 8 band 10 are 774.89 Watts $\cdot \mathrm{m}^{-2} \cdot \mathrm{srad}^{-1} \mu \mathrm{m}^{-1}$ and $1321.08 \mathrm{~K}$, respectively. $L_{\lambda}$ is the thermal infrared band after radiation calibration and COST atmospheric correction.

3.3. Estimation of Land Surface Emissivity. In this study, we applied two LSE (LSE1 and LSE2) estimation methods; both methods are based on NDVI. The first method LSE1 refers to the NDVI threshold method proposed by Sobrino [30] calculated by the following equation:

$$
\varepsilon=0.004 P_{v}+0.986,
$$

where $\varepsilon$ is the LSE and $P_{v}$ is calculated according to NDVI using the following equation:

$$
P_{v}=\frac{\left(\mathrm{NDVI}-\mathrm{NDVI}_{\mathrm{soil}}\right)}{\left(\mathrm{NDVI}_{\mathrm{veg}}-\mathrm{NDVI}_{\mathrm{soil}}\right)},
$$

where $\mathrm{NDVI}_{\text {soil }}$ is the NDVI value of bare soil or areas without vegetation coverage and $\mathrm{NDVI}_{\mathrm{veg}}$ is the NDVI value of pixels completely covered by vegetation, namely, the NDVI value of pure vegetation pixels. Empirical values $\mathrm{NDVI}_{\text {veg }}=0.6$ and $\mathrm{NDVI}_{\text {soil }}=0.05$ were taken; that is, when the NDVI of a pixel is greater than $0.60, P_{v}$ value is 1.0 , and when NDVI is less than $0.05, P_{v}$ value is 0 .

The other method LSE2 is to firstly divide the surface into water, natural surface, and urban area according to the method proposed by Qin et al. [31] and then calculate the LSE for the three types of surface separately. The calculation is by the following equation:

$$
\varepsilon=\left\{\begin{array}{cc}
0.995 & \text { water } \\
0.9625+0.0614 P_{v}-0.0461 P_{v}^{2} & \text { natural surface } \\
0.9589+0.086 P_{v}-0.0671 P_{v}^{2} & \text { urban area }
\end{array}\right\} .
$$

However, the concept of natural surfaces and urban areas is vague and cannot be quantitatively calculated. Based on remote sensing images of Beijing and its surrounding areas, we conducted local experiments and found that when NDVI is less than 0.05 , it corresponds to water; when NDVI is greater than or equal to 0.05 or less than or equal to 0.6 , it corresponds to urban areas; and when NDVI is greater than 0.6 , it corresponds to the natural surface. The calculation is in the following equation:

$$
\varepsilon=\left\{\begin{array}{cc}
0.995 & \mathrm{NDVI}<0.05 \\
0.9625+0.0614 P_{v}-0.0461 P_{v}^{2} & 0.05 \leq \mathrm{NDVI}<0.6 \\
0.9589+0.086 P_{v}-0.0671 P_{v}^{2} & 0.6 \leq \mathrm{NDVI}
\end{array}\right\} .
$$

3.4. Land Surface Temperature Inversion Algorithm. Based on four commonly used LST inversion methods (RTE, SC, $\mathrm{MW}$, and SW), a total of nine schemes were designed based on different parameters such as LSE and water vapor content $(w)$. The input atmospheric parameters such as downwelling radiance $\left(L \downarrow, W / m^{2} / s r / \mu m\right)$, upwelling radiance $\left(L \uparrow, W / m^{2} / s r / \mu m\right)$, water vapor content $\left(g \cdot \mathrm{cm}^{-2}\right)$, and atmospheric transmittance $(\tau)$ were calculated using the Atmospheric Correction Parameter Calculator (ACPC, https://atmcorr.gsfc.nasa.gov) developed by National Aeronautics and Space Administration (NASA) of the US $[32,33]$.

3.4.1. RTE Inversion Methods. The RTE is a direct method for LST retrieval using a single TIR band. This can be given by the following equation:

$$
L_{\lambda}=\left[\varepsilon B\left(T_{s}\right)+(1-\varepsilon) L \downarrow\right] \tau+L \uparrow,
$$

where $L_{\lambda}\left(w \cdot m^{-2} \cdot s r^{-1} \cdot \mu m^{-1}\right)$ is the brightness value of TIRS received by satellite sensor and $\lambda$ is the tenth band of TIRS. At present, the accuracy of the eleventh band calibration of TIRS is still not quantified, and USGS still does 
not encourage the use of eleventh band for relevant surface temperature inversion, so we only consider the tenth band in the RTE and SC. $\varepsilon$ refers to the LSE, $B\left(T_{s}\right)$ is the blackbody radiance energy, and $B\left(T_{s}\right)$ at a temperature of $T_{s}$ is calculated by the inversion of the following equation:

$$
B\left(T_{s}\right)=\left[L_{\lambda}-L \uparrow-\tau(1-\varepsilon) L \downarrow\right] \tau \varepsilon,
$$

and, eventually, $T_{s}$ can be obtained from the inversion of Planck's law as in the following equation:

$$
T_{s}=\frac{K_{2}}{\ln \left(K_{1} / B\left(T_{s}\right)+1\right)} .
$$

3.4.2. SC Inversion Methods. Jiménez-Muñoz et al. [20] proposed a revised version of SC for LST retrieval using Landsat TIR data. Concerning the SC, $T_{s}$ is obtained from the following equations:

$$
\begin{gathered}
T_{s}=\gamma\left[\varepsilon^{-1}\left(\psi_{1} L+\psi_{2}\right)+\psi_{3}\right]+\delta, \\
\gamma=\frac{T^{2}}{\left(b_{\gamma} L\right)}, \delta \approx T-\frac{T^{2}}{b_{\gamma}},
\end{gathered}
$$

where $b_{\gamma}$ is equal to $1320 \mathrm{~K}$ for Landsat- 8 band 10 and $L$ and $T$ are obtained by equation (1) and equation (6), respectively. $\psi_{1}, \psi_{2}, \psi_{3}$ is a function of water vapor content $(w)$ expressed in the following equation:

$$
\begin{aligned}
& \psi_{1}=p_{11} w^{2}+p_{12} w+p_{13}, \\
& \psi_{2}=p_{21} w^{2}+p_{22} w+p_{23}, \\
& \psi_{3}=p_{31} w^{2}+p_{32} w+p_{33},
\end{aligned}
$$

where $p_{i j}(i=1,2,3, j=1,2,3)$ is the parameter related to $w$. Perhaps because the calibration of TIRS band 11 is still unstable, Jiménez-Muñoz et al. only gave specific parameters for TIRS band 10:

$$
p=\left\{\begin{array}{ccc}
0.04019 & 0.02916 & 1.01523 \\
-0.38333 & -1.50294 & 0.20324 \\
0.00918 & 1.36072 & -0.27514
\end{array}\right\} .
$$

When $w \geq 3 \mathrm{~g} \cdot \mathrm{cm}^{-2}$, the accuracy of LST will be significantly affected, so Jiménez-Muñoz suggests using equation (18) to calculate $\psi_{1}, \psi_{2}, \psi_{3}$ :

$$
\begin{aligned}
& \psi_{1}=\frac{1}{\tau}, \\
& \psi_{2}=\frac{-L \downarrow-L \uparrow}{\tau}, \\
& \psi_{3}=L \downarrow .
\end{aligned}
$$

3.4.3. MW Inversion Methods. Mono Window (MW) algorithm was originally developed for Landsat TM data. Later, some scholars evaluated the ability of MW to process
Landsat ETM + data and Landsat- 8 data, which can be used in the following equation:

$$
T_{s}=\frac{\left\{a \cdot(1-C-D)+[b \cdot(1-C-D)+C+D] \cdot T-D \cdot T_{a}\right\}}{C},
$$

where $T_{a}$ is the effective mean atmospheric temperature and $a$ and $b$ values for the Landsat- 8 band 10 are -67.355 and 0.458606, respectively. $C=\varepsilon \cdot \tau$ and $D=(1-\tau)[1+$ $(1-\varepsilon) \cdot \tau]$. Table 2 provides empirical equations to estimate $T_{a}$ through air temperature $\left(T_{o}\right)$, since it is an essential parameter of MW (Zhang et al. 2016). In this study, $T_{a}$ was computed for the mid-latitude summer and winter region and $T_{o}$ was obtained from the mean of all meteorological stations.

3.4.4. SW Inversion Methods. Although the USGS does not encourage users to use band 11 calculations, some researchers have developed a Split Window algorithm for Landsat- 8 that references other satellite two-channel algorithms. Jiménez-Muñoz et al. [21] proposed a revised version of SW for LST retrieval using Landsat TIRS data. The algorithm is simple to calculate. After the brightness temperature of band 10 and band 11 of TIR is obtained, it can be calculated by the following equation:

$$
\begin{aligned}
T_{s}= & T_{10}+c_{1}\left(T_{10}-T_{11}\right)+c_{2}\left(T_{10}-T_{11}\right)^{2}+c_{0} \\
& +\left(c_{3}+c_{4} w\right)\left(1-\varepsilon_{m}\right)+\left(c_{5}+c_{6} w\right) \Delta \varepsilon,
\end{aligned}
$$

where $T_{10}$ and $T_{11}$ are the brightness temperatures of band 10 and band 11 and $\varepsilon_{m}$ is the average LSE of band 10 and band 11. $\Delta \varepsilon$ is the LSE interpolation of band 10 and band 11 . In this study, the LSE of main ground objects was obtained through ASTER spectral library, and the estimated value of three NDVI segments in equation (10) was matched through the calculation of the average value of LSE of relevant ground objects. Table 3 shows the estimated LSE. $w$ is the water vapor content $(w)$, and the values of parameters $c_{0} \sim c_{6}$ are $-0.268,1.378,0.183,54.3,-2.238,-129.2$, and 16.4 , respectively.

Rozenstein et al. [25] proposed an SW algorithm for inversion of land surface temperature using Landsat-8 TIR data based on the MW algorithm of QIN [23]. The algorithm is expressed by the following equations:

$$
\begin{gathered}
T_{s}=A_{0}+A_{1} T_{10}-A_{2} T_{11}, \\
A=\frac{D_{10}}{E_{0}}, \\
E_{0}=D_{11} C_{10}-D_{10} C_{11}, \\
E_{1}=\frac{D_{11}\left(1-C_{10}-D_{10}\right)}{E_{0}}, \\
E_{2}=\frac{D_{10}\left(1-C_{11}-D_{11}\right)}{E_{0}}, \\
C_{i}=\varepsilon_{i} \tau_{i}(\theta), \\
D_{i}=\left[1-\tau_{i}(\theta)\right]\left[1+\left(1-\varepsilon_{i}\right) \tau_{i}(\theta)\right],
\end{gathered}
$$


TABLE 2: The linear equations for the calculation of the effective mean atmospheric temperature $\left(T_{a}\right)$ from the near-surface air temperature $\left(T_{o}\right)$.

\begin{tabular}{lc}
\hline Region & Linear equations \\
\hline USA 1976 region & $T_{a}=25.940+0.8805 \times T_{o}$ \\
Tropical region & $T_{a}=17.977+0.9172 \times T_{o}$ \\
Mid-latitude summer region & $T_{a}=16.011+0.9262 \times T_{o}$ \\
Mid-latitude winter region & $T_{a}=19.270+0.9112 \times T_{o}$ \\
\hline
\end{tabular}

TABLE 3: Estimation of the associated LSE.

\begin{tabular}{lccc}
\hline Band & NDVI $<0.05$ & $0.05 \leq$ NDVI $<0.6$ & $0.6 \leq$ NDVI \\
\hline TIRS 10 & 0.9908 & 0.9451 & 0.9824 \\
TIRS 11 & 0.9901 & 0.9503 & 0.9819 \\
\hline
\end{tabular}

where $\quad A_{0}=E_{1} a_{10}-E_{2} a_{11}, A_{1}=1+A-E_{1} b_{10}, A_{2}=$ $A+E_{2} b_{11}, A_{0}, A_{1}, A_{2}$ are the parameters determined by atmospheric transmittance and LSE, and $a_{i}, b_{i}$ are, respectively, the regression coefficients of band 10 and band 11 determined according to different temperature ranges; this is shown in Table 4. In this study, parameters with temperature ranging from $0^{\circ} \mathrm{C}$ to $40^{\circ} \mathrm{C}$ were selected. $\varepsilon_{i}$ is the LSE of band 10 and band 11. $\tau_{i}(\theta)$ is the atmospheric transmittance corresponding to the solar zenith angle. Rozenstein et al. provided the relationship between atmospheric transmittance and atmospheric water vapor content, as shown in Table 5; namely, atmospheric transmittance was estimated by atmospheric water vapor content, which was also the calculation method in this paper. In this study, the parameters determined by mid-latitude summer are selected.

3.5. Validation Method and Performance Metrics. In this study, based on four commonly used LST inversion methods and different parameters, a total of nine schemes are designed, which are shown in Table 6.

The T-based technique, examined in this research, is a direct way of comparing the satellite-derived LST with measured temperatures at meteorological stations [34-38]. The capability of the T-based technique depends mostly on the accuracy of the measured temperatures at meteorological stations and pixel scale effect. The major benefit of the T-based method is that the accuracy of LST algorithm can be accurately evaluated [39]. In this study, satellite-derived LST and station-based LST were analyzed considering the performance metrics such as Root Mean Square Error (RMSE) and average Bias [40]. The formulas of these metrics are as follows:

$$
\begin{aligned}
\text { RMSE } & =\sqrt{\frac{\sum\left[T_{L 8}-T_{\text {station }}\right]^{2}}{n}}, \\
\text { BIAS } & =\frac{\sum\left[T_{L 8}-T_{\text {Station }}\right]}{n},
\end{aligned}
$$

where $T_{L 8}$ and $T_{\text {Station }}$ are the Landsat-8-derived LST and station-based LST, respectively, and $n$ refers to the number of pieces of data; in this study, $n$ is equal to 20 .
TABLE $4: a_{i}$ and $b_{i}$ over different temperature ranges.

\begin{tabular}{lcccc}
\hline Temperature ranges & $a_{10}$ & $b_{10}$ & $a_{11}$ & $b_{11}$ \\
\hline $0 \sim 30^{\circ} \mathrm{C}$ & -59.1391 & 0.4213 & -63.3921 & 0.4565 \\
$0 \sim 40^{\circ} \mathrm{C}$ & -60.9196 & 0.4276 & -65.2240 & 0.4629 \\
$10 \sim 40^{\circ} \mathrm{C}$ & -62.8065 & 0.4338 & -67.1728 & 0.4694 \\
$10 \sim 50^{\circ} \mathrm{C}$ & -64.6081 & 0.4399 & -69.0251 & 0.4756 \\
\hline
\end{tabular}

TABLE 5: Relationship between atmospheric transmittance and atmospheric water vapor content.

\begin{tabular}{lccc}
\hline Profile & Estimation equation & $R^{2}$ & SEE \\
\hline \multirow{2}{*}{1976 U.S. Standard } & $\tau_{10}=-0.1146 w+1.0286$ & 0.9882 & 0.0094 \\
& $\tau_{11}=-0.1568 w+1.0083$ & 0.9947 & 0.0086 \\
\hline \multirow{2}{*}{ Mid-latitude summer } & $\tau_{10}=-0.1134 w+1.0355$ & 0.986 & 0.1010 \\
& $\tau_{11}=-0.1546 w+1.0078$ & 0.996 & 0.0073 \\
\hline
\end{tabular}

TABLE 6: Different LST inversion methods.

\begin{tabular}{lcc}
\hline Model & Model + parameter & Model ID \\
\hline \multirow{2}{*}{ RTE } & RTE (LSE1, $\tau, L \uparrow, L \downarrow)$ & LST1 \\
& RTE (LSE2, $\tau, L \uparrow, L \downarrow)$ & LST2 \\
\hline \multirow{3}{*}{ SC } & SC $(w)$ & LST3 \\
& SC (LSE1, $\tau, L \uparrow, L \downarrow)$ & LST4 \\
\multirow{2}{*}{ SW } & SC (LSE2, $\tau, L \uparrow, L \downarrow)$ & LST5 \\
& SW (by Jiménez-Muñoz et al.) (LSE2, w) & LST6 \\
\multirow{2}{*}{ MW } & SW (by Rozenstein et al.) (LSE2, w) & LST7 \\
& MW (LSE1, $\tau, L \uparrow, L \downarrow)$ & LST8 \\
& MW (LSE2, $\tau, L \uparrow, L \downarrow)$ & LST9 \\
\hline
\end{tabular}

Inputs of parameters such as LSE, up radiance, down radiance, atmospheric transmittance, atmospheric water and gas content, and atmospheric average temperature are needed in the inversion algorithm. Each of the above parameters is not directly measured by the instrument but has been estimated and processed. The errors of these inputs of parameters will affect the accuracy of LST inversion. Sensitivity analysis is an application of how the errors (numerical, statistical, or otherwise) of the model output are divided and allocated to different sources of uncertainty in the model input [41]. The following equation is utilized:

$$
S_{e}=T_{s}(x)-T_{s}(x+\Delta x)
$$

where $x$ represents one of the input parameters and $\Delta x$ is the step size of the parameter setting. In the study species, atmospheric transmittance $(\tau)$, emissivity, and NDVI were set as 0.01 , upwelling radiance and downwelling radiance were set as 0.1 unit, water vapor content $(w)$ was set as 0.1 unit, mean surface temperature was set as 1 unit, and $S_{e}$ was the LST difference calculated for each increase in step size; $T_{s}(x+\Delta x)$ and $T_{s}(x)$ refer to the LST calculated for " $x+\Delta x$ " and " $x$," respectively.

\section{Results and Analysis}

In order to accurately evaluate the accuracy of the LST inversion algorithm, measured data from 20 meteorological stations in the study area were used to evaluate the stability 
of the inversion results of different LST inversion algorithms in different seasons. In addition, considering the difference of inversion results of the same reflectivity ground objects by different LST inversion algorithms, we designed two groups of experimental areas inside the city and outside the city. Each experimental area has four types of ground objects, respectively, and each type of ground object has 20 POIs. Finally, we analyzed the dependence of different LST inversion algorithms on parameters by equal step size.

4.1. Comparison of the Results of Different LST Inversion Algorithms. Nine LST inversion algorithms were used to calculate Landsat-8 data in four seasons in the research area. The results were compared with the measured temperatures of 20 meteorological stations. The results are shown in Figure 2. By comparing the inversion results of each algorithm with the measured data, the statistical Root Mean Square Error (RMSE) and average Bias are shown in Table 7 of Appendix. It can be obtained from Figure 2 and Appendix's Table 7 that the inversion results of the LST algorithm are entirely consistent with the graph trend of the measured data of meteorological stations. The high elevation meteorological sites (e.g., Foyeding, Yanqing, Tanghekou, and Zhaitang) were low. In the graphic display, the line with the measured data of adjacent stations shows a concave shape. All LST inversion algorithms also have the same characteristics. In terms of seasonal scale, the inversion results of the nine algorithms in winter have the highest matching degree with the measured data of meteorological stations. The values of RMSE and Bias were relatively small. Followed by the data in autumn, the matching degrees in spring and summer were inferior. The values of RMSE and Bias were relatively large. In winter, the inversion results of LST1, LST2, LST3, LST4, and LST5 were the closest to the measured data of meteorological stations, with difference of less than $2^{\circ} \mathrm{C}$, followed by the inversion results of LST6, which were $3^{\circ} \mathrm{C}$ higher than the measured data, and the difference between the inversion results of LST7, LST8, and LST9 and the measured data was about $7^{\circ} \mathrm{C}$. In spring and summer, almost all the algorithm inversion results were higher than the measured temperature. At this time, the closest to the measured temperature were LST1, LST2, LST4, and LST5, with difference of about $5^{\circ} \mathrm{C}$, followed by LST3 inversion results, about $10^{\circ} \mathrm{C}$. The inversion results of LST8 and LST9 were $20^{\circ} \mathrm{C}$ higher than the measured results, and the reliability of the results will be seriously questioned. In autumn, the inversion results of LST1, LST2, LST4, and LST5 were slightly lower than the measured data by $2^{\circ} \mathrm{C}$, the inversion results of LST3 were $5^{\circ} \mathrm{C}$ higher than the measured data, and the inversion results of LST6, LST7, LST8, and LST9 were $8^{\circ} \mathrm{C}$ higher than the measured data.

From the perspective of the algorithm inversion results, the inversion results of LST1, LST2, LST4, and LST5 were the closest to the measured data of meteorological stations, with the inversion error within $\pm 5^{\circ} \mathrm{C}$, followed by the inversion results of LST3 at about $10^{\circ} \mathrm{C}$. The worst are the inversion results of LST6, LST7, LST8, and LST9, with the inversion error around $20^{\circ} \mathrm{C}$. In general, in the season with low temperature, the error of the inversion results of the algorithm was smaller than that of the measured data. With the increase of temperature, the inversion results of all the inversion algorithms were higher than those of the measured data. LST1, LST2, LST4, and LST5 have a relatively small error, followed by LST3 LST6, LST7; the inversion errors of LST8 and LST9 were relatively large.

We performed linear fitting between nine LST inversion results and measured temperatures in four seasons. The fitting results are shown in Figure 3. According to the statistical fitting results, it can also be seen that, in winter, all the relevant results were relatively ideal, with $R^{2}$ greater than 0.73. Except for the two SW algorithms LST6 and LST7, the fitting slopes of the other algorithms were all less than 1 . The fitting results in autumn show that $R^{2}$ was around 0.5 , and all the fitting slopes were less than 1 . However, the relevant intercept data are relatively large. In spring and summer, the proper slopes were more significant than 1 . The absolute value of the fitting intercept was also relatively large. It is important to note that the fitting results of the LST7 algorithm in spring, summer, and autumn show no significant phenomenon; that is to say, the error between the inversion results of the LST7 algorithm and the measured results is unacceptable.

Overall, the inversion results of the RTE and SC algorithm calculated by LSE1 and LSE2 have an excellent fitting effect with the measured data; the inversion results of the SC algorithm are calculated by $w$. The inversion result of MW was higher compared to the measured temperature. The inversion effect of SW was not particularly ideal, which may be caused by the instability of the radiation calibration of the 11th band of TIRS.

4.2. Results on Different POIs. It is well known that intensive human activities affect the surrounding environment. Industrial production and emissions affect atmospheric transmittance, water vapor content, and upward and downward radiation. All LST inversion algorithms need these parameters to support the calculation. Therefore, it is necessary to explore whether the inversion results of similar surface features with the same reflectivity in densely populated cities and outside cities close to the natural surface will be affected by various inversion algorithms and to what extent. The four selected ground objects (20 POIs for each ground object) were analyzed inside and outside the city. Considering the statistical error, $10 \%-90 \%$ of the points were selected as the upper and lower whiskers of the box map, and the upper and lower boundaries of the box represented $25 \%-75 \%$ of the values, respectively. The result is shown in Figure 4.

As shown in Figure 4, in the same season, the same LST inversion algorithm results show that the height of the box map inside the city was less than the height of the box map outside the city. The standard deviation of inversion results of all LST inversion algorithms on POI inside the city was less than the standard deviation of inversion results outside the city. On the one hand, the main reason may be the urban heat island effect and on the other hand it may be the 


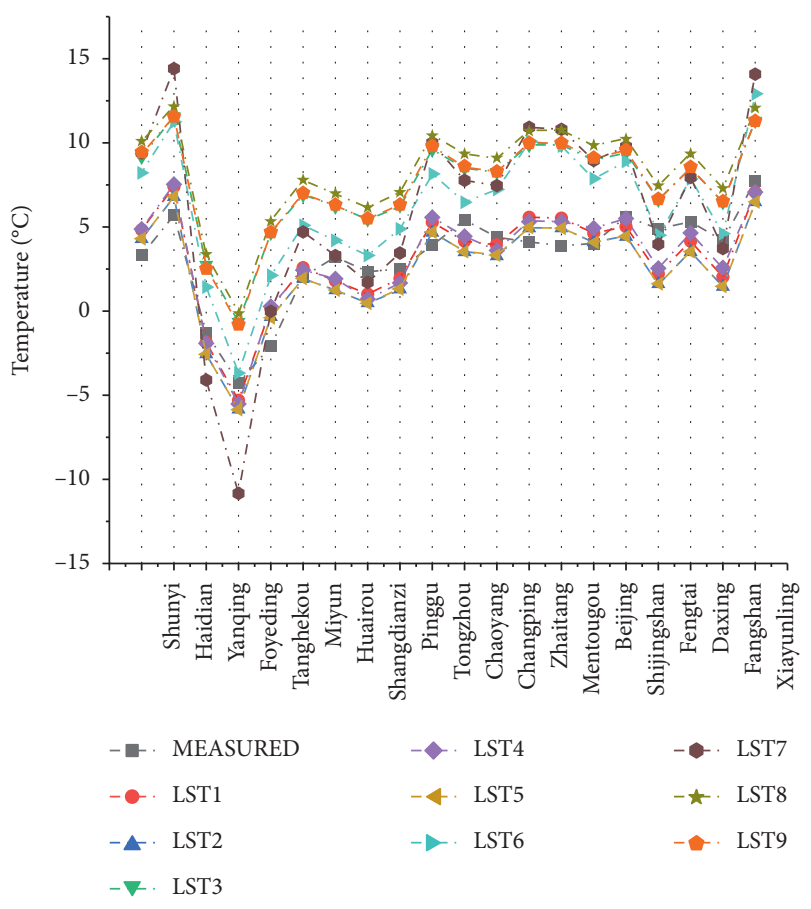

(a)



(c)

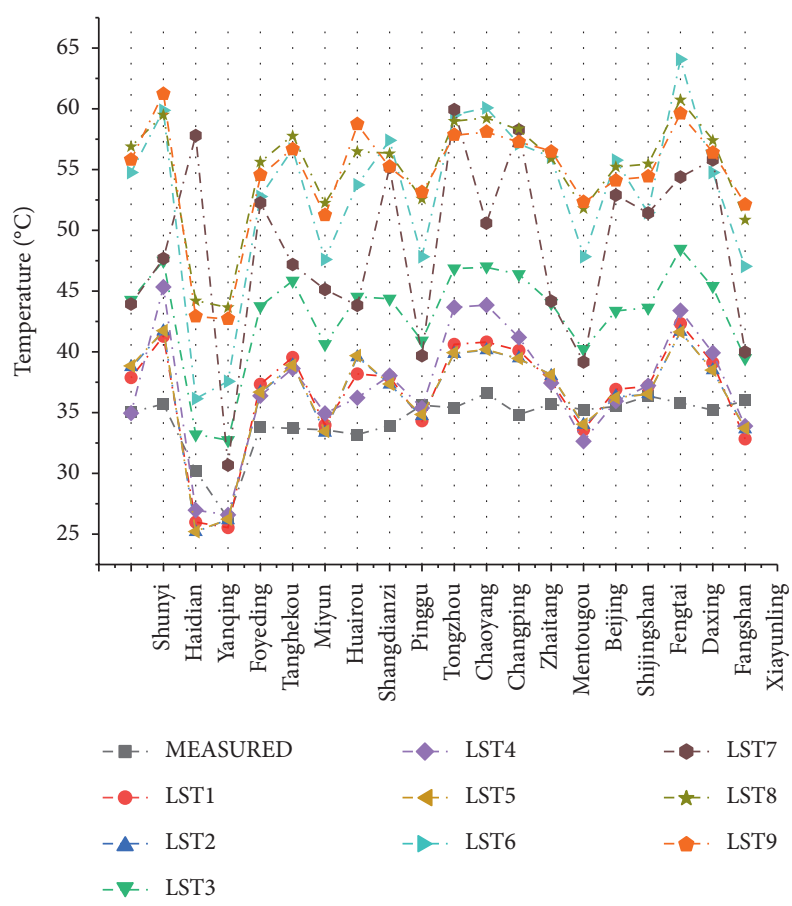

(b)

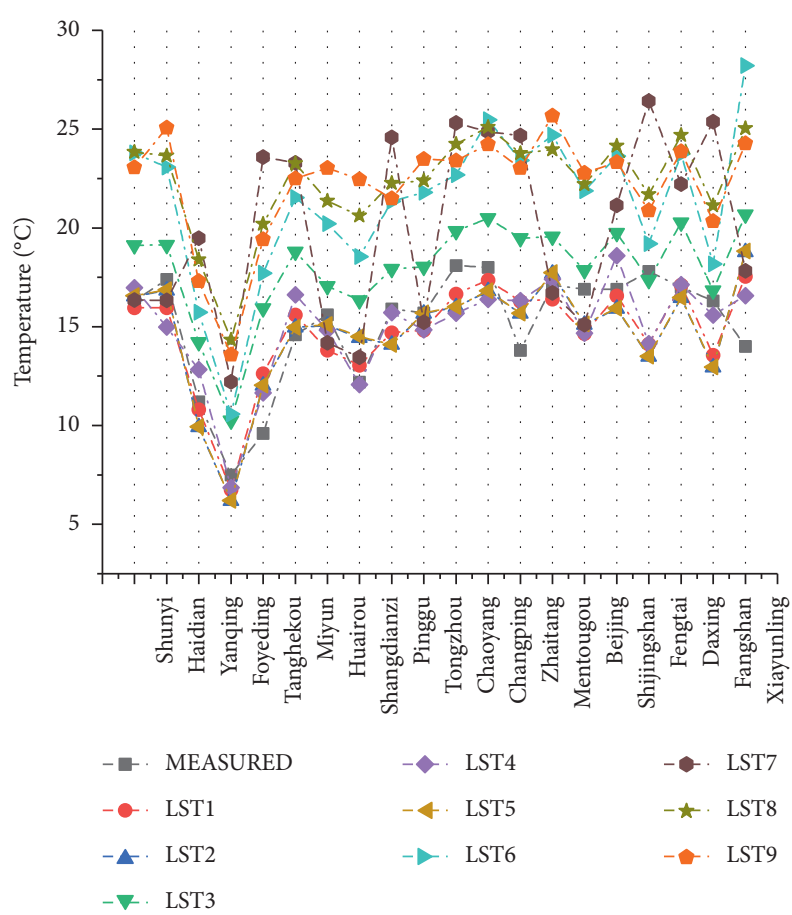

(d)

FIGURE 2: Inversion results of 9 LST inversion algorithms at 20 meteorological stations in different seasons. (a) 2017-01-31 (winter), (b) 201705-17 (spring), (c) 2017-7-10 (summer), and (d) 2017-10-30 (autumn).

influence of intensive human activities inside the city on the parameters of the inversion algorithm. In addition, in a relatively narrow space, using the same estimated parameters for calculation, the inversion results are relatively concentrated. However, the outer space of the city is relatively broad, which belongs to the natural surface. There are differences in estimated atmospheric parameters, and the inversion results will be different in different outer areas. As a result, the inversion results of land surface temperature are relatively scattered.

Both inside and outside the city, the height of the water box chart is minimal. The POI inversion temperature difference between inside the city and outside the city is about $1^{\circ} \mathrm{C}$ in autumn. The average inversion temperature of POI 
TABLE 7: Root Mean Square Error (RMSE), average bias, slope, intercept, and $R^{2}$ of LST inversion and field measured temperature.

\begin{tabular}{|c|c|c|c|c|c|c|}
\hline Season & Model ID & RMSE & Bias & Slope & Intercept & $R^{2}$ \\
\hline \multirow{9}{*}{ Winter } & LST1 & 0.67 & -0.15 & 0.94 & 0.04 & 0.775 \\
\hline & LST2 & 3.24 & -0.73 & 0.94 & -0.54 & 0.772 \\
\hline & LST3 & 18.89 & 4.22 & 0.91 & 4.52 & 0.775 \\
\hline & LST4 & 0.27 & -0.06 & 0.98 & 0.01 & 0.794 \\
\hline & LST5 & 3.23 & -0.72 & 0.94 & -0.53 & 0.772 \\
\hline & LST6 & 13.54 & 3.03 & 1.16 & 2.51 & 0.738 \\
\hline & LST7 & 11.80 & 2.64 & 1.89 & -0.24 & 0.771 \\
\hline & LST8 & 22.42 & 5.01 & 0.93 & 5.24 & 0.776 \\
\hline & LST9 & 19.20 & 4.29 & 0.93 & 4.52 & 0.772 \\
\hline \multirow{9}{*}{ Spring } & LST1 & 10.18 & 2.28 & 1.42 & -12.30 & 0.535 \\
\hline & LST2 & 9.54 & 2.13 & 1.38 & -11.03 & 0.531 \\
\hline & LST3 & 39.09 & 8.74 & 1.33 & -2.57 & 0.531 \\
\hline & LST4 & 12.33 & 2.76 & 1.49 & -14.05 & 0.472 \\
\hline & LST5 & 9.79 & 2.19 & 1.38 & -11.02 & 0.530 \\
\hline & LST6 & 82.87 & 18.53 & 2.11 & -19.69 & 0.469 \\
\hline & LST7 & 63.14 & 14.12 & 1.04 & 12.86 & 0.055 \\
\hline & LST8 & 91.98 & 20.57 & 1.44 & 5.31 & 0.532 \\
\hline & LST9 & 90.20 & 20.17 & 1.52 & 2.28 & 0.561 \\
\hline \multirow{9}{*}{ Summer } & LST1 & 11.12 & 2.49 & 1.32 & -8.99 & $\overline{0.459}$ \\
\hline & LST2 & 11.49 & 2.57 & 1.28 & -7.39 & 0.498 \\
\hline & LST3 & 65.02 & 14.54 & 1.16 & 8.88 & 0.450 \\
\hline & LST4 & 11.47 & 2.57 & 1.33 & -9.16 & 0.458 \\
\hline & LST5 & 11.86 & 2.65 & 1.28 & -7.52 & 0.499 \\
\hline & LST6 & 84.98 & 19.00 & 1.49 & 1.65 & 0.411 \\
\hline & LST7 & 72.96 & 16.32 & 1.36 & 3.32 & 0.121 \\
\hline & LST8 & 53.96 & 12.07 & 1.35 & 0.32 & 0.465 \\
\hline & LST9 & 55.89 & 12.50 & 1.25 & 0.28 & 0.500 \\
\hline \multirow{9}{*}{ Autumn } & LST1 & 1.68 & -0.38 & 0.69 & 4.35 & 0.592 \\
\hline & LST2 & 1.63 & -0.37 & 0.72 & 3.89 & 0.522 \\
\hline & LST3 & 12.74 & 2.85 & 0.66 & 7.94 & 0.591 \\
\hline & LST4 & 0.45 & -0.10 & 0.70 & 4.36 & 0.607 \\
\hline & LST5 & 1.53 & -0.34 & 0.72 & 3.90 & 0.519 \\
\hline & LST6 & 27.62 & 6.17 & 0.93 & 7.30 & 0.459 \\
\hline & LST7 & 21.57 & 4.82 & 0.52 & 12.06 & 0.055 \\
\hline & LST8 & 32.28 & 7.22 & 0.70 & 11.81 & 0.599 \\
\hline & LST9 & 31.58 & 7.06 & 0.74 & 10.97 & 0.573 \\
\hline
\end{tabular}

inside the city is about $3^{\circ} \mathrm{C}$ higher than that outside the city in other seasons. It shows that the standard deviation of all LST inversion algorithms on POI of the water body is minimal, which also conforms to the characteristics of the water body being relatively stable, and LSE is close to the black body.

Surprisingly, the height of the box chart of vegetation in all categories is considerable. Among all the POI inversion temperatures of vegetation outside the city in spring, the POI inversion temperature difference of vegetation outside the city is about $5^{\circ} \mathrm{C}$ (this value does not count LST7 because it is precarious). The POI inversion temperature difference of other vegetations is $8^{\circ} \mathrm{C}$. It indicates that the standard deviation of all LST inversion algorithms on vegetation POI is substantial, indicating that inversion algorithms are more sensitive to vegetation inversion, which will be explained in detail in the next section. In addition, it is also possible that when selecting pure pixels of vegetation, the vegetation types of pixels are different. Some pixels are grassland, some are woodland, and some are shrubs. Although these are all vegetation pixels, their reflectivity is inconsistent, which may lead to specific errors.

The box graph of soil POI temperature retrieved by the SW (LST6 and LST7) algorithm is relatively large; in particular, the LST7 algorithm is very obvious. The height of the box graph of soil POI temperature retrieved by other algorithms is relatively tiny, with a difference of about $4^{\circ} \mathrm{C}$ outside the city and $3^{\circ} \mathrm{C}$ inside the city. It shows that the standard deviation of all LST inversion algorithms on soil POI is minimal. It is worth noting that, in the selection of soil POI in this paper, the soil is dry and bright areas were selected instead of the dark soil with high moisture content to avoid the error caused by the significant difference in reflectivity.

Except for LST6 and LST7, the height of the box graph of building POI inversion by other LST inversion algorithms is small, with a difference of about $5^{\circ} \mathrm{C}$ outside the city and $3^{\circ} \mathrm{C}$ inside the city, indicating that the standard deviation of inversion results of all LST inversion algorithms on building POI is also small. 

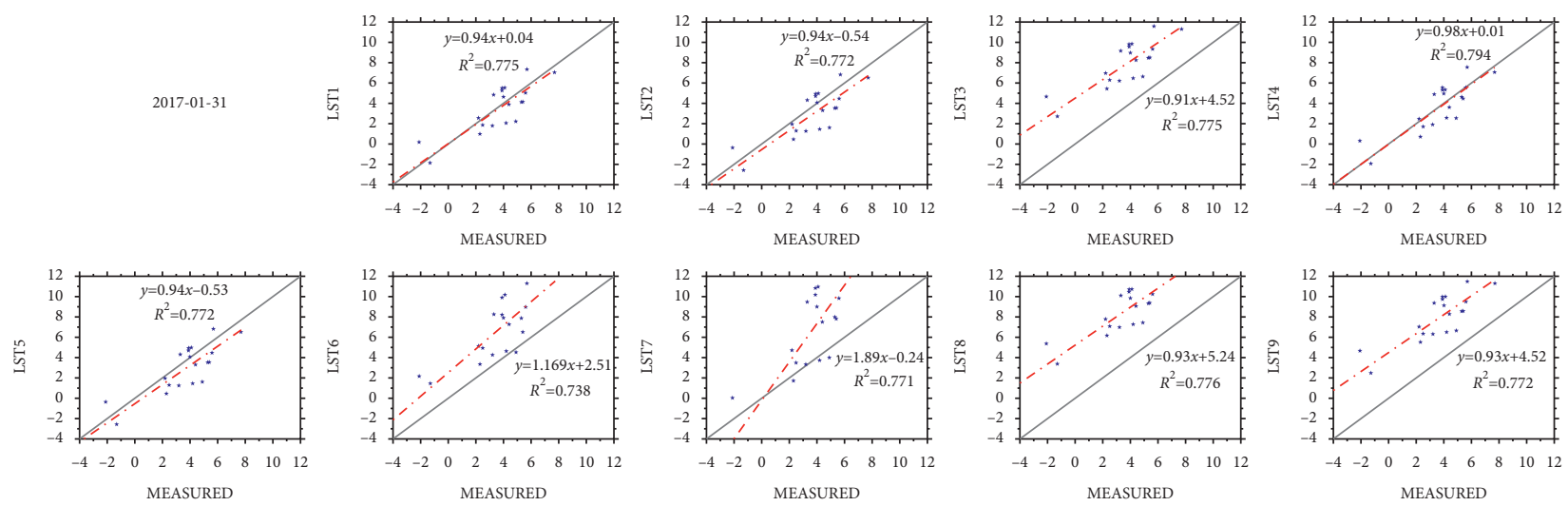

2017-05-07


MEASURED
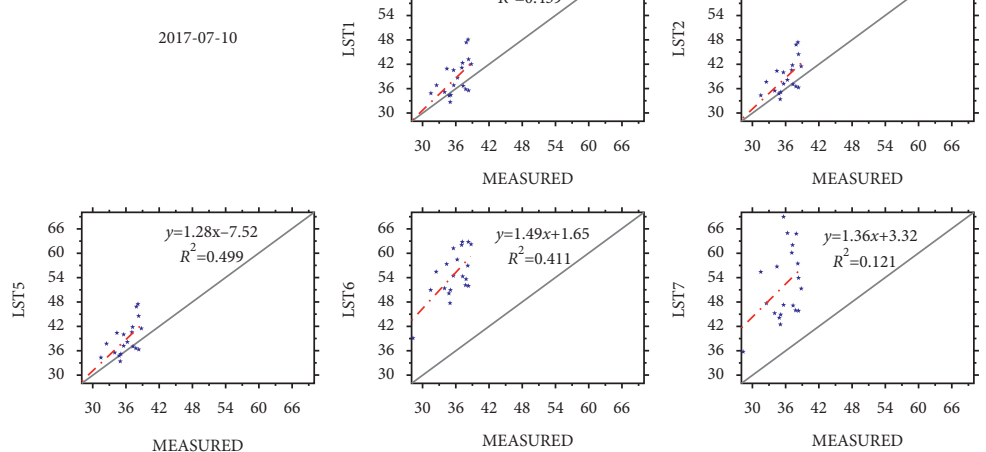

MEASURED
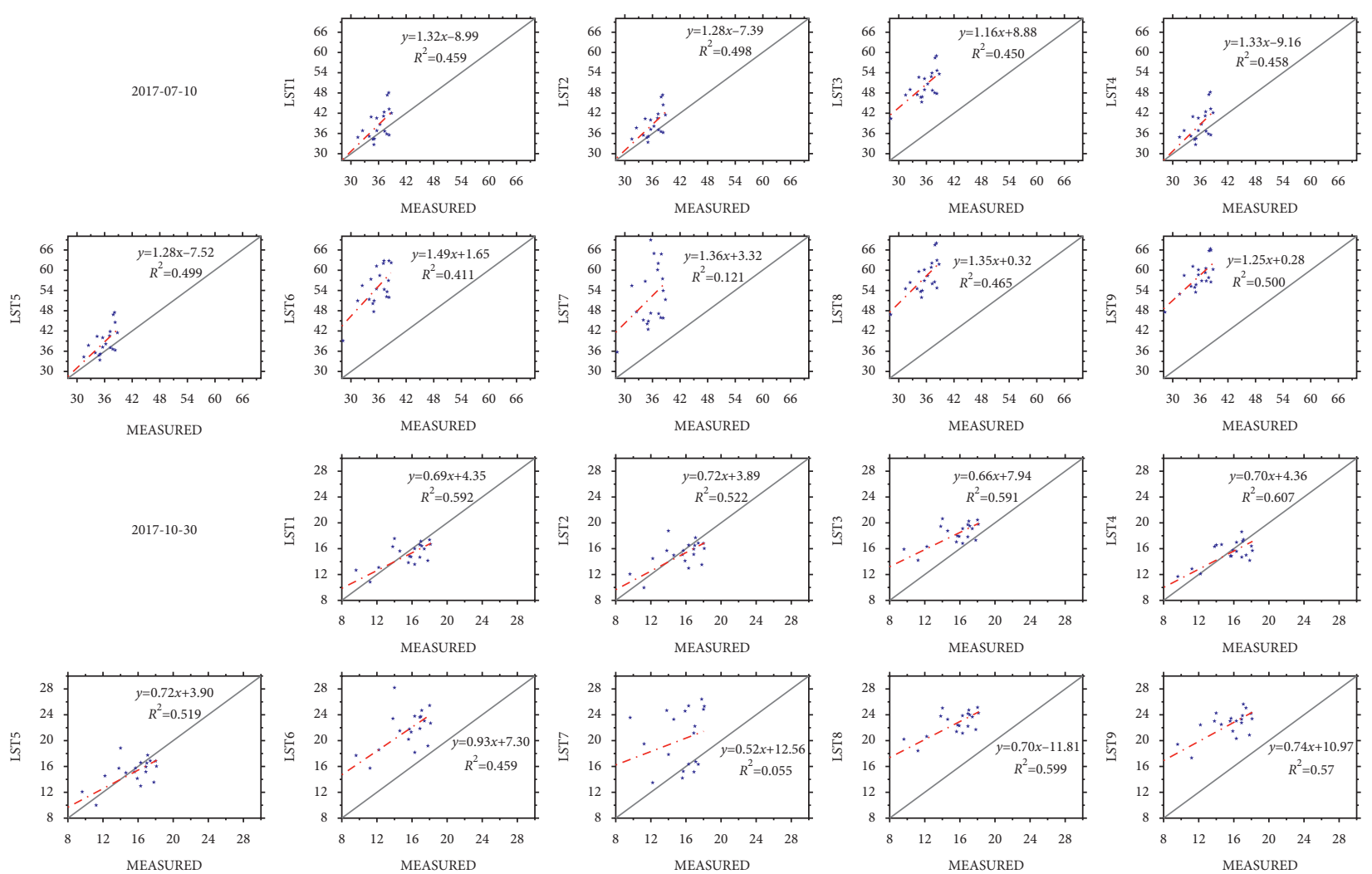

FIgURE 3: LST inversion results are fitted with the measured temperature. 




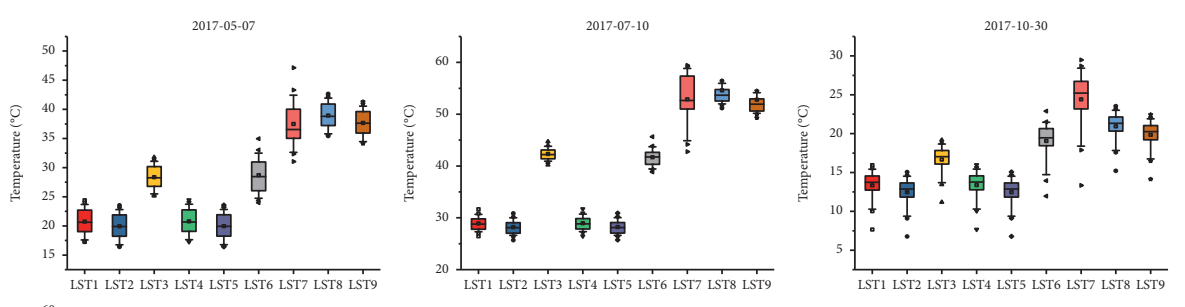

(1)
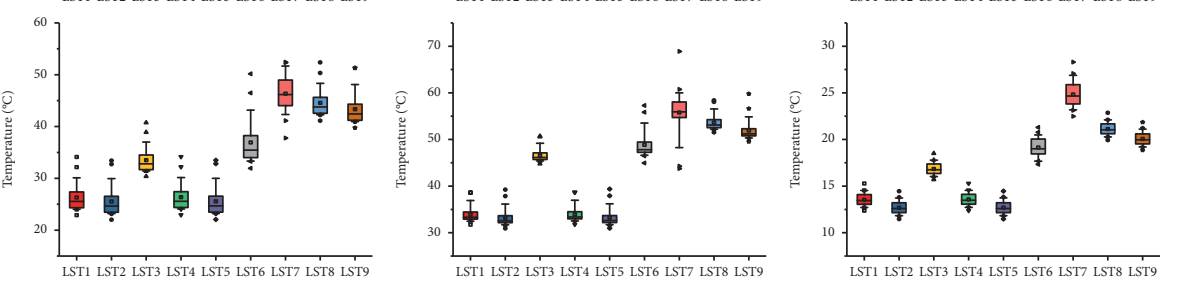




II)
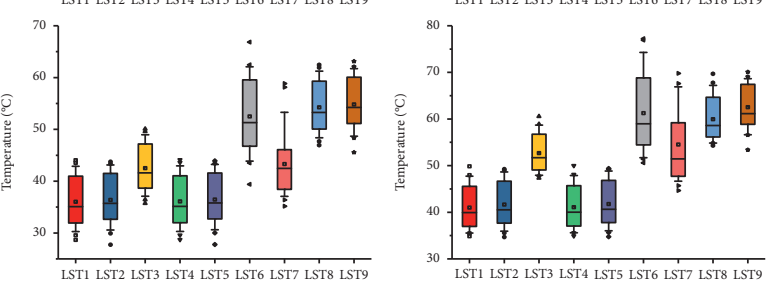

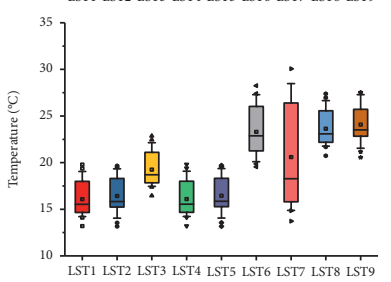

1 当



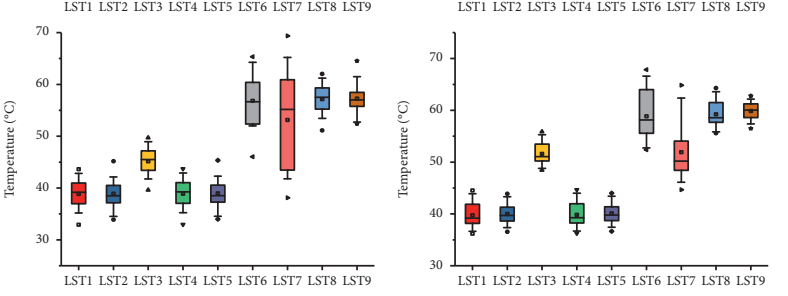

LST1 LST2 LST3 LST4 LST5 LST6 LST7 LST8 LST9

III

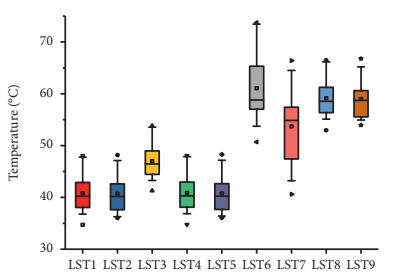

4 indi

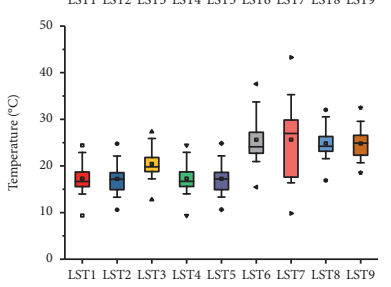

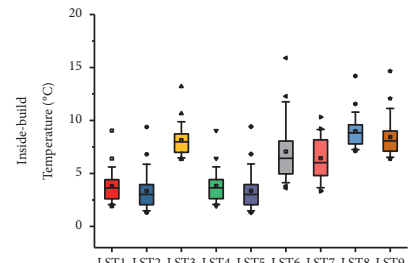
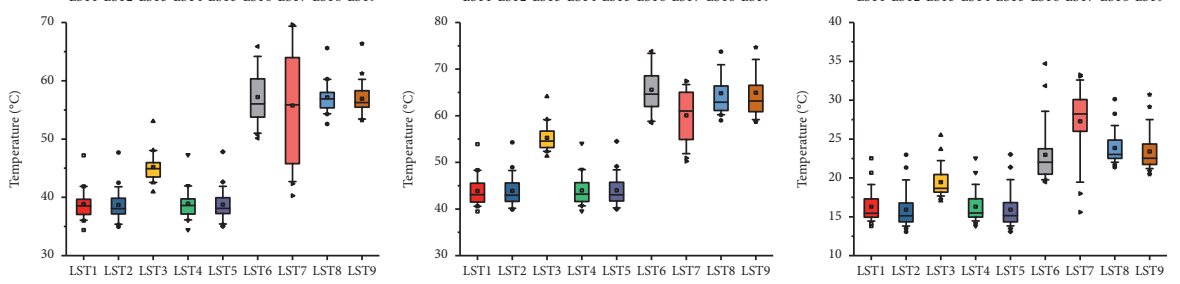

FIgURE 4: Inversion results of POI inside and outside the city by various algorithms. 
4.3. Sensitivity Analysis of Model Parameters. This paper adopts the control variable method to conduct sensitivity analysis for different parameters to explore the sensitivity of various LST inversion algorithms to parameters. First, assume all the DN values on the image are the same (in this study, take the average of the band after atmospheric correction; band 10 is set to 10.4 and band 11 is set to 9.4). Then select a group of parameters as variables, and the rest as invariants to control the variation of variable parameters for sensitivity analysis. Finally, the sensitivity of the parameters was analyzed. As the data with good weather conditions were selected in the remote sensing image screening previously, the interval of atmospheric transmittance is set as $0.5 \sim 1.0$ with a step size of 0.01 unit, and the interval of surface reflectance is set as $0.9 \sim 1.0$ with a step size of 0.01 unit. The interval of DNVI is set as $-0.2 \sim 1.0$ with a step size of 0.01 units. The interval of upward and downward radiation is set as $0 \sim 5$, and the step size is set as 0.1 units; the interval of atmospheric water vapor content is set as $0-2.5$, and the step size is set as 0.1 units; the interval of average surface temperature is set as $0-100$, and the step size is set as 1 unit. The influence of each parameter on the results in different algorithms was obtained by controlling variables. For the comparability of the results, LST was normalized, as shown in Figure 5.

It can be seen from Figure 5(a) that the influence of atmospheric transmittance on the inversion algorithms of RTE, SC, and MW is a logarithmic function. With the increase of atmospheric transmittance, the inversion of land surface temperature gradually decreases. The atmospheric transmittance has a minor effect on the curvature of RTE (LST1 and LST2) and a more significant effect on the curvature of SC (LST4 and LST5) and MW (LST8 and LST9). Figure 5(b) shows that the influence of specific emissivity on all algorithms is linear. As the specific emissivity increases, the land surface temperature decreases linearly. When the emissivity increases by 0.1 units, the inversion surface temperature decreases by 1 unit. Figure 5(c) shows that the influence of NDVI on LST1, LST3, LST4, and LST8 is piecewise linear. Segmentation is because, during parameter setting, specific emissivity is segmenting according to NDVI mandatory threshold. Specific emissivity is set as a fixed value for parts with NDVI less than 0.05 and DNVI greater than 0.6. The inversion temperature is also a fixed value. For the part with DNVI greater than 0.05 and less than 0.6, the specific emissivity changed with the change of NDVI. The inversion temperature decreased linearly with the increase of NDVI. The influence of NDVI on LST2, LST5, and LST9 is also segmenting. However, when NDVI is more than 0.05 , the influence of NDVI on LST presents a quadratic function; when NDVI is equal to 0.4 , the function has a minimum value; when NDVI is more than 0.05 and less than 0.4 , the inversion LST decreases the NDVI. When the NDVI is more than 0.4, the inversion LST increases the NDVI.

In Figure 5(d), the influence of uplink radiation on the SC (LST4 and LST5) algorithm is linear. With the increase of uplink radiation, the land surface temperature inversion by the SC algorithm decreases linearly. The influence of upline radiation on the RTE (LST1 and LST2) algorithm is logarithmic. However, the curvature of the curve is minimal. With the increase of upline radiation, the surface temperature retrieved by the RTE algorithm also decreases. As shown in Figure 5(e), the influence of downward radiation on the SC and RTE algorithm is linear. As downward radiation increases by 1 unit, the inversion land surface temperature decreases by 0.2 units. As shown in Figure 5(f), the influence of atmospheric water vapor content on LST3 and LST6 is linear. As the atmospheric water vapor content increases by 0.1 units, the surface temperature retrieved by LST3 and LST6 increases by about 0.3 units. The influence of atmospheric water vapor content on LST7 is nonlinear. With the increase of atmospheric water vapor, the LST retrieved by LST7 also increases, but the saturated phenomenon appears after 2.5. This result is consistent with the result of Jiménez et al. (2010). In Figure $5(\mathrm{~g})$, the average land surface temperature parameters required in the MW algorithm are presented. It can be seen that, with the increase of the average land surface temperature by 1 unit, the inversion of the land surface temperature by MW decreases by 0.01 units.

\section{Discussion}

NASA's ACPC obtains the atmospheric parameters required for the LST inversion method based on the MODTRAN radiation transfer code. It is not possible to find atmospheric profiles in situ (radiosonde data, etc.) at any time and any place. Therefore, even if this use (simulating atmospheric profiling information with ACPC) affects the accuracy of the method, it is clear from our results and the literature $[8,10,14,18,20,22-24,29-33]$ that NASA's ACPC provides an excellent and effective simulation. The development of the LST inversion method has its source of error, as it involves parameterization steps for inverting the coefficients and estimating some initial parameters. Therefore, it is necessary to compare the errors of various algorithms in the system. In general, the inversion results of the RTE algorithm and SC algorithm calculated by LSE1 and LSE2 have an excellent fitting effect with the measured data. The inversion results of MW are higher compared to the measured temperature. The inversion effect of SW is not particularly ideal, which may be due to the instability of radiation calibration at band 11 of TIRS. Hanqiu [42] used SC (LST3 and LST4) and SW (LST8 and LST9) algorithms to invert the LST in Fuzhou on August 4, 2013, and concluded that the SC result was better than the SW result. The inversion error of LST4 was $-2.77^{\circ} \mathrm{C}$. However, since the atmospheric water vapor content parameter was more than 4 on that day, the error of LST3 is $-17.44^{\circ} \mathrm{C}$, and the inversion errors of LST8 and LST9 are $-13.61^{\circ} \mathrm{C}$ and $-5.75^{\circ} \mathrm{C}$, respectively. Wang [41] compared the sensitivity analysis of the three algorithms, SC, MW, and SW, and found that SW had the lowest sensitivity to the input parameter error. Asia Siddiqui et al. [19] selected the data of two landscapes in January and April to study the heat island in Bangalore, India, based on the RTE method and found that the relationship between LST and NDVI was firstly positively correlated and then negatively correlated. 


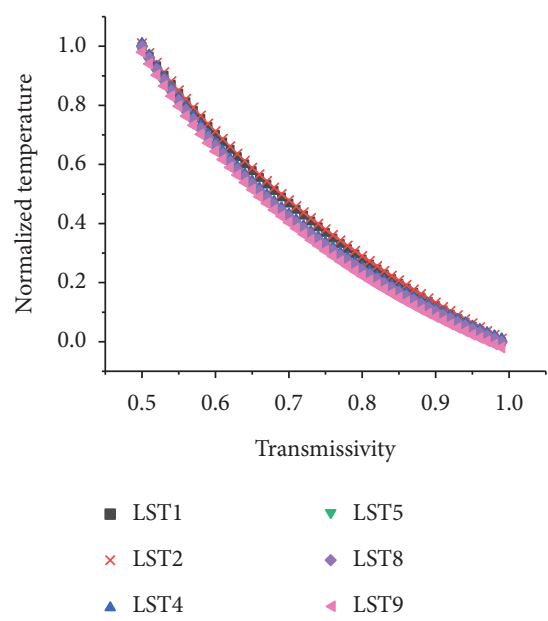

(a)

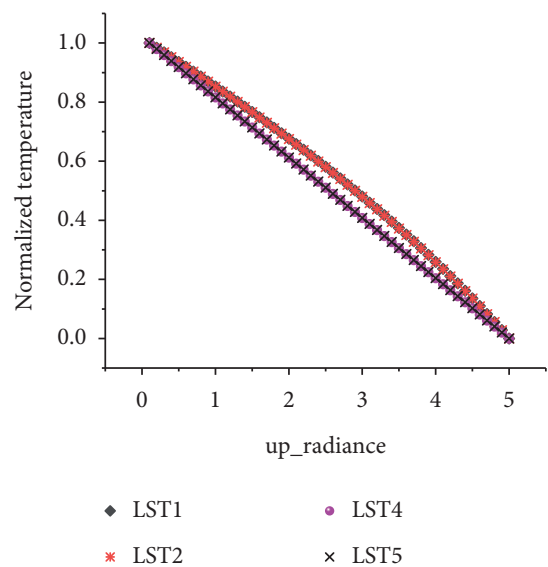

(d)



(b)



(e)

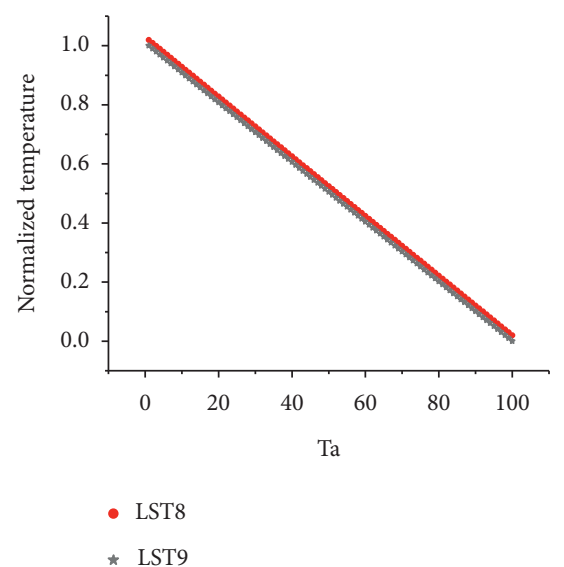

(g)

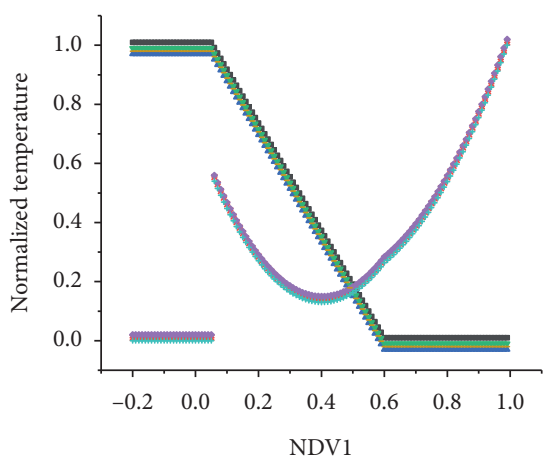

$$
\begin{array}{ll}
\text { - LST1 } & \text { - LST5 } \\
\text { * LST2 } & \text { - LST8 } \\
\text { \ LST3 } & \text { + LST9 } \\
\text { จ LST4 } &
\end{array}
$$

(c)

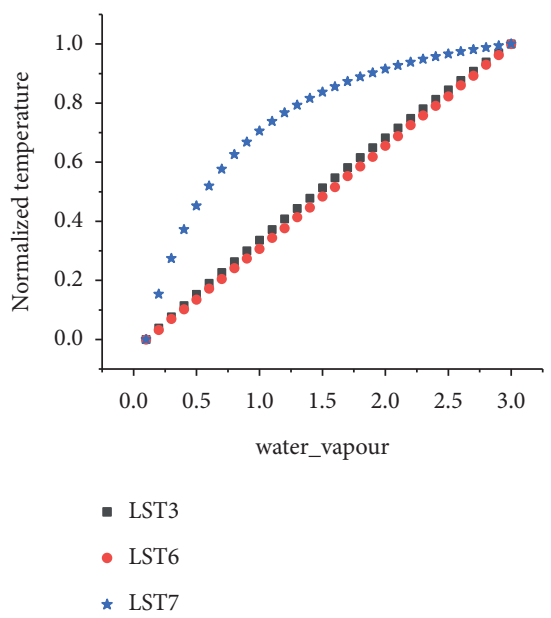

(f)

FIgURE 5: Sensitivity analysis of parameters of various LST inversion algorithms. The vertical axis represents the normalized LST, and the horizontal axis represents the parameters of each variable. The units of parameters are given in Section 3.

The various LST inversion algorithms are most stable in winter, and the stability becomes worse in other seasons. Aliihsan Sekertekin and Stefania Bonafoni [40] used Landsat-5, Landsat-7, and Landsat- 8 data to retrieve surface temperature from rural areas and found that RTE and SC presented similar results regardless of the season, while MW differed from RTE and SC for all seasons, especially in summer. The parameter error had little influence on the 
results in the humid environment. MW and SC methods are more sensitive to the error of input parameters, especially under hot and humid conditions. This result is consistent with our inversion results in urban areas. On the one hand, with the increase of temperature, the properties of ground objects (specific heat capacity and specific emissivity) have distinct differences, leading to a significant difference in reflectivity and then resulting in a significant difference in the inversion of surface temperature. On the other hand, considering the errors of surface temperature inversion of similar surface features POI from inside and outside the city, the increase of temperature will have a particular influence on the parameters of the LST inversion algorithm, which may lead to errors in the inversion results.

The stability of various inversion algorithms for temperature inversion inside and outside the city is tested. The results show that the standard deviations of inversion results for POIs of LST inversion algorithms in urban areas are smaller than those of inversion results outside the city. On the one hand, the main reason may be that the intensive human activities in cities have a particular influence on land surface temperature inversion parameters. On the other hand, the inversion results of the same reflectivity characteristics will be relatively concentrated when the same estimated parameters are used for calculation in a very narrow space inside the city. However, the space outside the city is relatively broad and belongs to the natural surface, so the estimated atmospheric parameters in different regions will be different, which may lead to the relatively scattered inversion results of land surface temperature.

It is essential to analyze the sensitivity/uncertainty of the LST inversion algorithm by considering all the input parameters. Sekertekin and Bonafoni's [43] simultaneous ground-based LST measurements were collected from Atmospheric Radiation Measurement (ARM) and Surface Radiation Budget Observing Network (SURFRAD) stations, located at different rural environments of the United States to examine the efficiency of different LST algorithms, using both daytime and nighttime Landsat- 8 data and in situ measurements. Concerning the in situ sensitivity results, the effects on LST of the uncertainty of the downwelling and upwelling radiance were almost identical in daytime and nighttime. The accuracy of the LST retrieval methods for daytime Landsat- 8 data varied between $2.17 \mathrm{~K}$ Root Mean Square Error (RMSE) and 5.47 K RMSE considering all LST methods and LSE models. MW with two different LSE models presented the best results for the daytime. Wang et al. [44] presented an improved Mono Window (IMW) algorithm for LST retrieval from the Landsat- 8 TIRS band 10 data, and sensitivity analysis conducted for the IMW algorithm revealed that the possible error in estimating the required atmospheric water vapor content has the most significant impact on the probable LST estimation error. This result is similar to our inversion results of LST3, LST6, and LST7. Although from our results and literature we can see clearly that NASA ACPC provides a satisfying and effective simulation, in our precise and fuzzy provided coordinates, respectively, phenology, area type (urban and rural), and satellite altitude parameters such as atmospheric profile parameters calculation, calculation results by ACPC difference are not very big; however, when we use the estimated atmospheric profile parameters for further calculation, there will be error propagation. Sensitivity analysis of the LST inversion algorithm can help researchers to understand the source of error and reduce the error as much as possible.

\section{Conclusions}

In all seasons, the inversion results of the nine LST algorithms are in complete agreement with the graph trends of the measured data of all meteorological stations. In winter, the inversion results of the nine algorithms have the highest matching degree with the measured data of meteorological stations, and the RMSE and Bias values are relatively small. The second is autumn's LST1, LST2, LST4, and LST5 inversion results of the nearest meteorological station, with inversion error of $\pm 5^{\circ} \mathrm{C}$; the following inversion result of LST3 is about $10^{\circ} \mathrm{C}$; the worst are the inversion results of LST6, LST7, LST8 and LST9, with inversion error of about $20^{\circ} \mathrm{C}$. In the low-temperature season, the error of the algorithm inversion results is less than that of the measured data. With the increase of temperature, the inversion results of each inversion algorithm are all higher compared to the measured data. The inversion errors of LST1, LST2, LST4, and LST5 are small, followed by LST3, LST6, LST7, LST8, and LST9.

According to the relevant results of the nine LST inversion results and the measured temperature, the fitting results in winter are all relatively ideal, with $R^{2}$ greater than 0.73 . In other seasons, the fitting effect is general, and $R^{2}$ is about 0.5 . In general, the inversion results of the RTE algorithm and SC algorithm calculated by LSE1 and LSE2 have an excellent fitting effect with the measured data, followed by the inversion results of the SC algorithm calculated by $w$. By analyzing the stability of various inversion algorithms inside and outside the city, it can be seen that the standard deviation of inversion results of each LST inversion algorithm for POI inside the city is less than that outside the city.

The influence of atmospheric transmittance on RTE, SC, and MW inversion algorithms is a logarithmic function. With the increase of atmospheric transmittance, the inversion surface temperature decreases gradually. The influence of emissivity on all algorithms is linear. The inversion of LST decreases by 1 for every 0.1 increase of emissivity. The influence of NDVI on LST1, LST3, LST4, and LST8 is piecewise linear, and the influence on LST2, LST5, and LST9 is in the form of a quadratic function. When NDVI is equal to 0.4 , the function has a minimum value. When NDVI is more than 0.05 and less than 0.4 , the inversion land surface temperature decreases. When NDVI is more than 0.4 , the inversion LST increases; this is the opposite of the previous results. The effect of uplink radiation on the SC (LST4 and LST5) algorithm is linear. With the increase of uplink radiation, the LST retrieved by the SC algorithm decreases linearly. The influence of upline radiation on the RTE (LST1 and LST2) algorithm is logarithmic. With the increase of upline radiation, the land surface temperature retrieved by the RTE algorithm decreases. The influence of 
downslope radiation on SC and RTE algorithms is linear. With the increase of downslope radiation by 1 unit, the inversion LST decreases by 0.2 units. The surface temperature retrieved by LST3 and LST6 increases by about 0.3 units for every 0.1 unit increase of atmospheric water vapor content. The influence of atmospheric water vapor content on LST7 is nonlinear. With the increase of atmospheric water vapor, the surface temperature retrieved by LST7 also increases, but, after 2.5 units, it shows saturation phenomenon.

\section{Data Availability}

Some or all data, models, or codes that support the findings of this study are available from the corresponding author upon reasonable request.

\section{Conflicts of Interest}

The authors declare that there are no conflicts of interest regarding the publication of this paper.

\section{Acknowledgments}

The National Key Research and Development Project of China (no. 2017YFA0605004) and Basic R\&D Special Fund of Central Government for Non-Profit Research Institutes (Grant/Award HKY-JBYW-2021-02) are acknowledged.

\section{References}

[1] M. Anderson, J. Norman, W. Kustas, R. Houborg, P. Starks, and N. Agam, "A thermal-based remote sensing technique for routine mapping of land-surface carbon, water and energy fluxes from field to regional scales," Remote Sensing of Environment, vol. 112, no. 12, pp. 4227-4241, 2008.

[2] P. Dash, F.-M. Göttsche, F.-S. Olesen, and H. Fischer, "Land surface temperature and emissivity estimation from passive sensor data: theory and practice-current trends," International Journal of Remote Sensing, vol. 23, no. 13, pp. 25632594, 2010.

[3] R. E. Dickinson, "Land surface processes and climate-surface albedos and energy balance," Advances in Geophysics, in Proceedings of a Symposium Commemorating the Two-Hundredth Anniversary of the Academy of Sciences of Lisbon, pp. 305-353, Lisbon, Portugal, October 1983.

[4] D. Tong, Q. Zhang, Y. Zheng et al., "Committed emissions from existing energy infrastructure jeopardize $1.5^{\circ} \mathrm{C}$ climate target," Nature, vol. 572, no. 7769, pp. 373-377, 2019.

[5] G. P. Peters, R. M. Andrew, J. G. Canadell et al., "Carbon dioxide emissions continue to grow amidst slowly emerging climate policies," Nature Climate Change, vol. 10, no. 1, pp. 3-6, 2019.

[6] B. Talukder, R. Matthew, G. W. Vanloon, M. J. Bunch, K. W. Hipel, and J. Orbinski, "Melting of Himalayan glaciers and planetary health," Current Opinion in Environmental Sustainability, vol. 50, pp. 98-108, 2021.

[7] J. Xin, X. Sun, and L. Liu, "Quantifying the contribution of climate and underlying surface changes to alpine runoff alterations associated with glacier melting," Hydrological Processes, vol. 35, no. 3, 2021.
[8] D. Zhou, J. Xiao, and S. Bonafoni, "Satellite remote sensing of surface urban heat islands: progress, challenges, and perspectives," Remote Sensing, vol. 11, no. 1, 2018.

[9] C. Keeratikasikorn and S. Bonafoni, "Urban heat island analysis over the land use zoning plan of bangkok by means of landsat 8 imagery," Remote Sensing, vol. 10, no. 3, 2018.

[10] J. A. Sobrino, R. Oltra-Carrió, and G. Sòria, "Evaluation of the surface urban heat island effect in the city of Madrid by thermal remote sensing," International Journal of Remote Sensing, vol. 34, no. 9-10, pp. 3177-3192, 2012.

[11] J. Tan, Y. Zheng, X. Tang et al., "The urban heat island and its impact on heat waves and human health in Shanghai," International Journal of Biometeorology, vol. 54, no. 1, pp. 75-84, 2010.

[12] C. Maffei, S. Alfieri, and M. Menenti, "Relating spatiotemporal patterns of forest fires burned area and duration to diurnal land surface temperature anomalies," Remote Sensing, vol. 10, no. 11, 2018.

[13] Z. Wan, P. Wang, and X. Li, "Using MODIS land surface temperature and normalized difference vegetation index products for monitoring drought in the southern great plains, USA," International Journal of Remote Sensing, vol. 25, no. 1, pp. 61-72, 2010.

[14] J. Sun, G. D. Salvucci, and D. Entekhabi, "Estimates of evapotranspiration from MODIS and AMSR-E land surface temperature and moisture over the Southern Great Plains," Remote Sensing of Environment, vol. 127, pp. 44-59, 2012.

[15] J. Qin, S. Liang, R. Liu, H. Zhang, and B. Hu, "A weakconstraint-based data assimilation scheme for estimating surface turbulent fluxes," IEEE Geoscience and Remote Sensing Letters, vol. 4, no. 4, pp. 649-653, 2007.

[16] B. Yong, L. Ren, Y. Hong et al., "First evaluation of the climatological calibration algorithm in the real-time TMPA precipitation estimates over two basins at high and low latitudes," Water Resources Research, vol. 49, no. 5, pp. 2461-2472, 2013.

[17] O. Hall, G. Falorni, and R. L. Bras, "Characterization and quantification of data voids in the shuttle radar topography mission data," IEEE Geoscience and Remote Sensing Letters, vol. 2, no. 2, pp. 177-181, 2005.

[18] J. C. Price, "Estimating surface temperatures from satellite thermal infrared data-A simple formulation for the atmospheric effect," Remote Sensing of Environment, vol. 13, no. 4, pp. 353-361, 1983.

[19] A. Siddiqui, G. Kushwaha, A. Raoof, P. A. Verma, and Y. Kant, "Bangalore: urban heating or urban cooling?" The Egyptian Journal of Remote Sensing and Space Science, vol. 24, no. 2, pp. 265-272, 2021.

[20] J. C. Jiménez-Muñoz and J. A. Sobrino, “A single-channel algorithm for land-surface temperature retrieval from ASTER data," IEEE Geoscience and Remote Sensing Letters, vol. 7, no. 1, pp. 176-179, 2010.

[21] J. C. Jiménez-Muñoz, J. Cristobal, J. A. Sobrino et al., "Revision of the single-channel algorithm for land surface temperature retrieval from landsat thermal-infrared data," IEEE Transactions on Geoscience and Remote Sensing, vol. 47, no. 1, pp. 339-349, 2009.

[22] Z. Qin, A. Karnieli, and P. Berliner, "A mono-window algorithm for retrieving land surface temperature from Landsat TM data and its application to the Israel-Egypt border region," International Journal of Remote Sensing, vol. 22, no. 18, pp. 3719-3746, 2010.

[23] K. Mao, Z. Qin, J. Shi, and P. Gong, "A practical split-window algorithm for retrieving land-surface temperature from 
MODIS data," International Journal of Remote Sensing, vol. 26, no. 15, pp. 3181-3204, 2007.

[24] Z. M. W. a. J. Dozier, "A generalized split- window algorithm for retrieving land-surface temperature from space," IEEE Transactions on Geoscience and Remote Sensing, vol. 34, no. 4, pp. 892-905, 1996.

[25] O. Rozenstein, Z. Qin, Y. Derimian, and A. Karnieli, "Derivation of land surface temperature for Landsat-8 TIRS using a split window algorithm," Sensors, vol. 14, no. 4, pp. 5768-5780, 2014.

[26] F.-M. G. Prasanjit Dash, F.-S. Olesen, and H. Fischer, "Retrieval of land surface temperature and emissivity from satellite data: physics, theoretical limitations and current methods," Journal of the Indian Society of Remote Sensing, vol. 29, no. 1, pp. 24-30, 2001.

[27] Y. Yu, D. Tarpley, J. L. Privette et al., "Validation of GOES-R satellite land surface temperature algorithm using SURFRAD ground measurements and statistical estimates of error properties," IEEE Transactions on Geoscience and Remote Sensing, vol. 50, no. 3, pp. 704-713, 2012.

[28] S. Pat and J. Chavez, "Image-based atmospheric corrections revisited and improved," Photogrammetric Engineering \& Remote Sensing, vol. 62, no. 9, pp. 1025-1036, 1996.

[29] X. Hanqiu, "Evaluation of two absolute radiometric normalization algorithms for pre-processing of landsat imagery," Journal of China University of Geosciences, vol. 17, no. 2, pp. 146-157, 2006.

[30] J. A. Sobrino, J. C. Jimenez-Munoz, G. Soria et al., "Land surface emissivity retrieval from different VNIR and TIR sensors," IEEE Transactions on Geoscience and Remote Sensing, vol. 46, no. 2, pp. 316-327, 2008.

[31] Z. Qin, W. Li, B. Xu, Z. Chen, and J. Liu, "The estimation of land surface emissivity for Landsat TM6," Remote sensing for land \& resources, vol. 3, no. 3, pp. 28-36, 2004.

[32] A. Julia, J. L. B. Barsi, and J. R. Schott, "An atmospheric correction parameter calculator for a single thermal band earth-sensing instrument," in IEEE International Geoscience \& Remote Sensing Symposium, Yokohama, Japan, August 2003.

[33] J. A. Barsi, J. J. Butler, and J. R. Schott, "Validation of a webbased atmospheric correction tool for single thermal band instruments," Earth Observing Systems X, vol. 10, 2005.

[34] N. K. Malakar, G. C. Hulley, S. J. Hook, K. Laraby, M. Cook, and J. R. Schott, "An operational land surface temperature product for landsat thermal data: methodology and validation," IEEE Transactions on Geoscience and Remote Sensing, vol. 56, no. 10, pp. 5717-5735, 2018.

[35] Z. Zhang, G. He, M. Wang, T. Long, G. Wang, and X. Zhang, "Validation of the generalized single-channel algorithm using Landsat 8 imagery and SURFRAD ground measurements," Remote Sensing Letters, vol. 7, no. 8, pp. 810-816, 2016.

[36] C. Coll, V. Caselles, J. Galve et al., "Ground measurements for the validation of land surface temperatures derived from AATSR and MODIS data," Remote Sensing of Environment, vol. 97, no. 3, pp. 288-300, 2005.

[37] X. Meng, J. Cheng, and S. Zhao, "Estimating land surface temperature from landsat- 8 data using the NOAA JPSS enterprise algorithm," Remote Sensing, vol. 11, no. 2, 2019.

[38] M. Wang, Z. Zhang, and T. Hu, "A practical single-channel algorithm for land surface temperature retrieval: application to landsat series data," Journal of Geophysical Research: Atmosphere, vol. 33, 2018.

[39] Z.-L. Li, B.-H. Tang, H. Wu et al., "Satellite-derived land surface temperature: current status and perspectives," Remote Sensing of Environment, vol. 131, pp. 14-37, 2013.
[40] A. Sekertekin and S. Bonafoni, "Land surface temperature retrieval from landsat 5,7 , and 8 over rural areas: assessment of different retrieval algorithms and emissivity models and toolbox implementation," Remote Sensing, vol. 12, no. 2, 2020.

[41] L. Wang, Y. Lu, and Y. Yao, "Comparison of three algorithms for the retrieval of land surface temperature from landsat 8 images," Sensors, vol. 19, no. 22, 2019.

[42] X. Hanqiu, "Retrieval of reflectivity and surface temperature from the newly launched Landsat 8 satellite," Chinese journal of geophysice, vol. 58, no. 3, pp. 741-747, 2015.

[43] A. Sekertekin and S. Bonafoni, "Sensitivity analysis and validation of daytime and nighttime land surface temperature retrievals from Landsat 8 using different algorithms and emissivity models," Remote Sensing, vol. 17, no. 12, p. 2776, 2020.

[44] F. Wang, Z. Qin, C. Song, L. Tu, A. Karnieli, and S. Zhao, “An improved mono-window algorithm for land surface temperature retrieval from Landsat 8 thermal infrared sensor data," Remote Sensing, vol. 4, no. 7, pp. 4268-4289, 2015. 